Gilson Lucio Rodrigues ${ }^{2}$

Luiz Eduardo Mantovani ${ }^{3}$

Uriel Duarte ${ }^{4}$

Kelita Lopes $^{5}$
${ }^{1}$ Trabalho extraído da Tese de Doutoramento de Gilson Lucio Rodrigues, intitulada Poeira e ruído na produção de brita a partir de basalto e gnaisse nas regiões de Londrina e Curitiba, Paraná: incidência sobre trabalhadores e meio ambiente, defendida em 2004, sob orientação do Professor Doutor Luiz Eduardo Mantovani, na Universidade Federal do Paraná.

${ }^{2}$ Doutor em Geologia pela Universidade Federal do Paraná (UFPR), pesquisador da Fundacentro.

${ }^{3}$ Professor Doutor do Departamento de Geologia da Universidade Federal do Paraná (UFPR).

${ }^{4}$ Professor Doutor do Instituto de Geociências da Universidade de São Paulo (USP).

${ }^{5}$ Graduanda em Geologia na Universidade Federal do Paraná (UFPR).

\section{Estudo comparativo entre as poeiras respiráveis de basalto e gnaisse na produção de brita nas regióes de Londrina e Curitiba, no estado do Paraná, e sua influência para os trabalhadores $^{1}$}

\author{
Comparative study of breathable dust \\ yielded by basalt and gneiss in the \\ production of crushed-stones from the \\ regions of Londrina and Curitiba, in the \\ state of Paraná, and their impact on workers
}

\begin{abstract}
Resumo
Este trabalho visa à análise comparativa entre as poeiras de basalto e gnaisse em empresas produtoras de brita nas regiões de Londrina e Curitiba, no estado do Paraná, através de avaliações ambientais apoiadas por análises químicas, petrográficas e morfoscópicas das rochas e das poeiras. Utilizou-se bomba de amostragem individual, munida com filtros de PVC, para coleta de partículas respiráveis nos trabalhadores e posterior análise por difração de raios-X para determinação de sílica livre cristalizada. As análises químicas e petrográficas foram feitas com amostras de rochas das frentes de lavra. Efetuou-se análise da morfologia e do tamanho das partículas na poeira com imagens obtidas no microscópio eletrônico de varredura. A concentração de poeira respirável apresentou valores consideráveis comparados à legislação. A porcentagem de $\mathrm{SiO}_{2}$ para o basalto ficou entre $1,0 \%$ e $5,4 \%$ e acima de $10 \%$ no gnaisse. O gnaisse mostrou-se $15 \%$ acima do basalto para partículas entre $0,5 \mu \mathrm{m}$ e $3,0 \mu \mathrm{m}$, com formas mais irregulares e fibrosas. Conclui-se que o gnaisse apresenta maior risco de formação de nódulos silicóticos (silicose clássica) e que o basalto apresenta maior probabilidade de provocar pneumoconioses por poeiras mistas.

Palavras-chaves: silicose, poeira, pedreira.
\end{abstract}

\begin{abstract}
The purpose of this study is to make a comparative analysis of the basalt and gneiss dust yielded by crushed-stone production in companies located in Londrina and Curitiba, two cities located in the State of Paraná, by carrying out environmental assessments backed by chemical, petrography and morphological analyses of rocks and dusts samples. An individual sampling pump fitted with PVC filters was attached to the workers' lapel to collect the breathable particles, which were later analyzed by X-ray diffraction to determine free crystallized silica. Samples collected at blasting site work-fronts were analyzed chemically and petrographically. The morphological analysis of dust particle size was performed with a sweeping electronic microscope. Breathable dust concentrations were high compared to the acceptable limits set by the environmental legislation. The rate of SiO2 for basalt ranged from 1.0 to 5,4\% and over $10 \%$ for gneiss. The rate of gneiss was 15\% higher than the rate of basalt for particles ranging from 0.5 to $3.0 \mu \mathrm{m}$, where particles are more irregular in shape and more fibrous. The study showed that gneiss-exposed workers are more prone to silicosis nodule formations (classical silicosis), while basalt is more conducive to mixed dust pneumoconiosis.
\end{abstract}

Keywords: silicosis, dust, crushed-stone. 


\section{Introdução}

O presente estudo trata da análise de poeira em função da produção de brita a partir de basalto e gnaisse. Conforme a Fundação Jorge Duprat Figueiredo de Segurança e Medicina do Trabalho - Fundacentro (1995), a poeira é definida como aerodispersóide composto por partículas sólidas produzidas por ruptura mecânica de sólidos.

A escolha de basalto e gnaisse deve-se ao fato dessas rochas serem as mais utilizadas na produção de brita no estado do Paraná.

Segundo a Associação Brasileira de Normas Técnicas - ABNT (1983), agregados podem ser definidos como materiais pétreos, gerados por fragmentação artificial ou natural, com propriedades adequadas, que atuam como elemento inerte, ou seja, não sofrem alterações químicas nas argamassas e nos concretos, estando aí incluídos a brita, a areia e o cascalho.

A mineração de agregados para construção civil junto a áreas urbanizadas fornece matérias-primas para a execução e manutenção das atividades urbanas. Conforme Santos (1988), a mineração, de uma forma geral, é uma atividade de fundamental importância para o desenvolvimento econômico e social de qualquer país, pois é nessa atividade que são obtidas as matérias-primas básicas para as indústrias e os agregados para a construção civil.

\section{Aspectos Socioeconômicos}

Com base em Valverde (2002), o ramo de atividade para produção de brita gera em torno de 15.000 empregos diretos. Com relação à produção, o estado de São Paulo lidera com $30 \%$ da produção nacional, seguido por Minas Gerais com 12\%, Rio de Janeiro com 9\%, Paraná com 7\%, Rio Grande do Sul com 6\% e Santa Catarina com $4 \%$.

O consumo anual de rocha britada por habitante nos EUA, em 2000, foi em torno de $5.700 \mathrm{~kg}$. Esse nível repete-se nos países industrializados, sendo o consumo anual por habitante na Europa Ocidental variante entre $5.000 \mathrm{~kg}$ e $8.000 \mathrm{~kg}$. No Brasil, o consumo médio encontra-se em torno de $2.000 \mathrm{~kg} /$ habitante/ano, representando as péssimas condições habitacionais, uma
Porém, a implantação de empreendimentos mineiros implica não só em benefícios, mas também em impactos adversos ao meio ambiente provocados por resíduos decorrentes do ambiente de trabalho, além de, muitas vezes, oferecer um ambiente desfavorável para os trabalhadores.

A poluição do ar por partículas resultantes das atividades de mineração provoca alterações do sistema respiratório dependendo de fatores determinantes, como natureza e tamanho das partículas, quantidade inalada e tempo de exposição (SOUNIS, 1991). Essas alterações podem ser permanentes ou temporárias, dependendo dos fatores acima expostos, além da susceptibilidade individual. As características de clivagem, a morfologia e as propriedades de superfície da sílica podem influenciar na sua ação sobre o sistema respiratório. Daí torna-se cada vez mais necessário que as empresas incorporem ao processo de produção métodos de trabalho corretos, tendo como meta um ambiente de trabalho salubre para seus trabalhadores, principalmente com relação ao material particulado.

Para realizar este estudo comparativo entre as poeiras de basalto e gnaisse, foi contemplada a solicitação dos proprietários para que as empresas estudadas não sejam identificadas, sendo as mesmas tratadas como X e Y para o basalto e $\mathrm{Z}$ para o gnaisse.

malha rodoviária deficiente, um serviço de saneamento ineficiente e falta de capacidade de investimento de um país com baixa renda per capita.

Segundo a Minerais do Paraná - Mineropar (1999), a produção de pedra britada no estado do Paraná concentra-se na Região Metropolitana de Curitiba e nas cidades de Cascavel, Guarapuava, Ponta Grossa, Londrina, Arapongas, Maringá e Campo Mourão, com aproximadamente $60 \%$ da produção estadual. O consumo de brita no estado encontra-se em torno de 500 kg/habitante/ano.

Com base em dados do Departamento Nacional da Produção Mineral - DNPM (2001), a produção nacional de pedras britadas é a terceira mais importante na pro- 
dução mineral brasileira, representando $4,22 \%$ em valor, sendo superada apenas pelo petróleo $(56,30 \%)$ e pelo minério de ferro $(13,26 \%)$, sendo que a mineração, o transporte e a manipulação deste último também resultam na geração de poeiras respiráveis.

A centralização do crescimento industrial nas grandes cidades resultou numa concentração da população nas suas áreas periféricas, geralmente à margem de qualquer planejamento urbanístico. Os terrenos situados no entorno das áreas de extração mineral foram, e estão sendo, cada vez mais ocupados. Esse fato não é exclusivo das grandes regiões metropolitanas, ocorrendo em praticamente todos os grandes e médios aglomerados urbanos. A condução técnica das atividades em algumas minerações sem cuidados específicos em relação à segurança para os trabalhadores e ao conforto ambiental das populações vizinhas resultou em uma convivência pouco amigável entre a comunidade e as empresas de mineração, conforme Empresa Paulista de Planejamento Metropolitano - Emplasa (1987). A minimização desse conflito tem sido iniciada por ações técnicas, objetivando diagnosticar, controlar e prevenir os principais problemas com relação aos trabalhadores e ao meio ambiente.

\section{Influência da Poeira para o Sistema Respiratório}

Segundo Braile et al. (1988), o material particulado mais importante, na atividade mineral, é o pó de pedra proveniente do beneficiamento da rocha e da movimentação dos equipamentos e veículos. As fontes de emissões são classificadas nos seguintes grupos:

\section{a) Emissões de processamento;}

b) Emissões fugitivas, provenientes das operações não fixas.

As partículas em suspensão são extremamente finas e têm grande poder de penetração no sistema respiratório, podendo atingir até os alvéolos, o que as torna altamente prejudiciais à saúde. As partículas menores que $100 \mu \mathrm{m}$ penetram no trato respiratório. Para que penetrem nos brônquios e nos alvéolos, é necessário que elas tenham tamanho inferior a $10 \mu \mathrm{m}$ (ALGRANTI, 1995). A retenção de poeira nos brônquios e nos alvéolos será mais intensa, dependendo da natureza da poeira, para as partículas cujo diâmetro varia de 0,5 a 3,0 $\mu \mathrm{m}$ (BASTARACHE, 2002).

As doenças pulmonares devidas à inalação de poeiras inorgânicas são chamadas pneumoconioses. A silicose é um tipo de pneumoconiose ocasionada pela inalação de poeiras contendo partículas finas de sílica livre e cristalina, sendo uma doença pulmonar crônica, incurável e irreversível. O termo sílica refere-se aos compostos de dióxido de silício $\left(\mathrm{SiO}_{2}\right)$ em suas diversas fases, incluindo sílica cristalina e amorfa. De uma forma geral, a silicose é uma doença crônica, geralmente ocorrendo após 10 anos de exposição à poeira, mesmo à baixa concentração, para que haja manifestação.
Porém, apresenta-se também nas formas acelerada e aguda, em que os sintomas começam a aparecer em período mais curto de exposição quando em concentrações elevadas (GOELZER, 2000).

Conforme De Capitani (1996), outro tipo de pneumoconiose é a fibrose pulmonar por poeira mista, que apresenta lesão morfológica diferenciada do nódulo silicótico provocada pela deposição de sílica livre associada a poeiras menos fibrogênicas, tais como óxido de alumínio, ferro e silicatos. A quantidade de sílica livre que resulta nessa situação é, em geral, menor que $10 \%$. Na fibrose pulmonar por poeira mista, a lesão apresenta configuração estrelada ou como "cabeça de medusa", mas os aspectos clínicos, radiológicos e prognósticos assemelham-se aos da silicose.

Segundo a Fundação Nacional de Saúde - Funasa (2002), o risco de silicose clássica existe quando o teor de sílica livre na fração de poeira respirável é maior que 7,5\%. Quando o teor de sílica livre encontra-se abaixo desse valor, as lesões anatomopatológicas são mais características do quadro que constitui a pneumoconiose por poeira mista.

Com base em Algranti (2002), estima-se que no Brasil o número de trabalhadores potencialmente expostos à poeira contendo sílica pode ser superior a 6 milhões, sendo que 500 mil têm atividade na mineração e no garimpo e acima de 2 milhões em indústrias de transformação de minérios, metalurgia e química. O maior percentual ocorre na indústria da construção civil, com cerca de 4 milhões de trabalhadores. 
A relação entre a sílica e o câncer de pulmão tem sido objeto de algumas publicações. Porém, as razões dessa associação ainda são polêmicas. É discutido se a exposição à sílica per se é suficiente para causar o câncer, embora biologicamente plausível, ou seria necessária a existência da silicose, pois a fibrogênese predispõe a carcinogênese (CARNEIRO, 2001).
Segundo a International Agency for Research on Câncer - IARC (1997), a sílica livre cristalina inalada na forma de quartzo ou cristobalita a partir de exposições ocupacionais é carcinogênica. Foram efetuados vários estudos epidemiológicos em diversos ramos de atividades em que existe a presença dessa substância, verificandose que um silicótico possui 1,5 a 6,0 vezes mais risco de adquirir câncer de pulmão do que um não silicótico.

\section{Características das Áreas Estudadas}

A área onde os estudos foram desenvolvidos, com relação ao basalto, está situada no Planalto de Apucarana, entre os rios Tibagi e Ivaí, ou seja, no Terceiro Planalto Paranaense. A constituição litológica da região é bastante homogênea, representada pelas rochas basálticas da formação Serra Geral. Essa formação é representada por vários derrames de lavas basálticas continentais, com variações químicas e texturais importantes resultantes de um dos mais volumosos processos vulcânicos continentais da Terra. Essas rochas são de textura geral afanítica, cor cinza escura a negra e amigdaloidais no topo dos derrames, estando as amígdalas normalmente preenchidas por quartzo, calcita e zeólitas (CUNHA \& GUERRA, 1998).

Com base no Instituto Agronômico do Paraná - IAPAR (2001), a região é beneficiada por um regime pluviométrico razoavelmente bem distribuído durante o ano, com precipitação média anual variando de 1.100 a $1.600 \mathrm{~mm}$ e raríssimos períodos de grandes estiagens ou chuvas prolongadas, sendo fevereiro e março os meses mais chuvosos. O índice de umidade relativa média anual situa-se em torno de $68 \%$. Entretanto, durante os meses de outono e inverno, constata-se várias semanas sem chuvas significativas, o que favorece a mobilização de poeira para o ar.

A região onde se localiza a empresa produtora de brita a partir do gnaisse encontra-se no Primeiro Planalto Paranaense, a oeste de Curitiba.

Segundo Maack (1968), o Primeiro Planalto divide-se em três sub-regiões particularmente típicas. Na região Sul, grandes extensões planas e suaves ondulações. A região Norte é recortada numa paisagem recente de elevações. Uma terceira parte à Leste é drenada por rios de meandros. Curitiba, a capital do estado, localiza-se na parte não entalhada e suavemente ondulada do Primeiro Planalto.

A rocha predominante é o gnaisse, ocupando quase 100\% da área pesquisada, sendo os corpos de dimensões desconhecidas pertencentes ao Complexo Atuba, possuindo granulação média, com tonalidades cinzas-esverdeadas e composições variando de mangeríticas a noríticas (SIGA JUNIOR, 1995).

Ocorrem diques de diabásio cortando discordantemente o gnaisse. O dique de maior dimensão corta a área no sentido $\mathrm{N} 55^{\circ}-60^{\circ} \mathrm{W}$, com largura de $20 \mathrm{~m}$. São rochas de cor escura, granulometria fina, que, ao alterarem, apresentam blocos em forma circular com típica esfoliação esferoidal, isto é, descamamento em formas arredondadas pela pressão dos fluidos presentes na rocha. A presença desses diques de diabásio não interfere no estudo comparativo entre as poeiras de basalto e gnaisse, pois apresenta composição semelhante à do basalto.

Segundo o Instituto Ambiental do Paraná - IAP (2001), a umidade relativa do ar na região varia entre $75 \%$ e $85 \%$. As precipitações ocorrem durante o ano inteiro com maior intensidade nos meses de verão. Apesar da maior umidade atmosférica média e da melhor distribuição de chuvas ao longo do ano, períodos secos podem ocorrer em qualquer estação, agravando e facilitando a mobilização de poeira.

\section{Descrição das empresas avaliadas}

As condições de operação de uma pedreira não são constantes, podendo ser afetadas por variação na demanda e na alimentação na britagem. Qualquer problema em um dos equipamentos prejudica o desempenho dos demais que compõem um circuito de britagem. Portanto, as con- 
centrações de material particulado podem variar num mesmo dia e de um dia para o outro.

A produção de brita, após o desmonte da rocha, é realizada pelo processo de britagem, rebritagem, peneiramento, distribuição em pilhas de acordo com a granulometria e transporte do material para seu destino.

A Empresa X produz brita a partir do basalto, possui 40 funcionários e tem uma produção média de $10.000 \mathrm{~m}^{3} / \mathrm{mês}$. A britagem apresenta o seguinte fluxo: um britador primário de mandíbula FAÇO 100x60 $\longrightarrow$ um britador secundário giratório FAÇO $13 \times 36 \rightarrow$ um britador terciário giratório FAÇO H 4.000 MC, existindo 04 pontos de peneiramento.

O sistema de controle de poeira é realizado com bicos de aspersão d'água no britador primário e nos pontos de descarga das correias transportadoras. A empresa não efetua a umectação das vias de trânsito e dos pátios de manobra.

A Empresa Y também utiliza basalto, possui 27 funcionários e apresenta uma

\section{Metodologia}

Inicialmente, efetuou-se levantamento qualitativo com objetivo de conhecer as características das empresas, levantar informações sobre as etapas de trabalho e identificar as fontes de exposição potencial à poeira de forma a selecionar os pontos para a coleta das amostras. Para tanto, percorreu-se todas as instalações de cada uma delas, procurando entender toda sua estrutura e funcionamento, analisando os locais de trabalho e as condições para desenvolvimento das tarefas ali exercidas. Verificou-se que as empresas pequenas não possuem qualquer sistema de controle ambiental, principalmente com referência ao material particulado, apresentando sistema de trabalho obviamente insatisfatório, não sendo necessária a amostragem para demonstrar o fato. Portanto, optou-se por estudar empresas que possuem equipamentos de controle coletivo para material particulado.

Após reconhecimento dos locais de trabalho, foram definidas para amostragem as funções de operadores da britagem primária, da britagem secundária e do carregamento por serem as que possuem produção média mensal de $3.000 \mathrm{~m}^{3} / \mathrm{mês}$. Sua capacidade instalada é de $4.500 \mathrm{~m}^{3} / \mathrm{mês}$ com os seguintes equipamentos: 01 britador primário de mandíbula FAÇO 62×40 $\longrightarrow 01$ rebritador de mandíbula FAÇO 90x26 $\longrightarrow 01$ britador cônico 90 FAÇO, intercalados por 03 pontos de peneiramento. O controle da poeira é efetuado de forma "primitiva", ou seja, com apenas um ponto de umidificação na transferência da correia transportadora, tendo sido implantadas algumas melhorias durante o decorrer do trabalho.

A empresa Z produz em média 20.000 $\mathrm{m}^{3} /$ mês de brita a partir do gnaisse. Conta atualmente com 24 funcionários e sua planta de britagem apresenta o seguinte fluxo: um britador primário Svedala, Jawmaster 11.08.HD $\longrightarrow$ um britador secundário (Hydrocone) S.3.000 $\longrightarrow$ um britador terciário (Hydropone) H.3.000 $\rightarrow$ um britador quaternário Barmac 6.000. O controle de poeira é efetuado com bicos de aspersão d'água nos britadores, nas correias transportadoras e em pontos de descarga. A empresa utiliza um caminhão pipa para umectação das vias internas de acesso.

o maior potencial de exposição ao agente estudado.

Os critérios aplicados nas avaliações ambientais obedeceram ao estabelecido na Norma de Higiene do Trabalho NHT-02 A/E - Avaliação da Exposição Ocupacional a Aerodispersóides, de maio/84, da Fundacentro.

A caracterização da exposição foi efetuada de forma individual com as amostras de material particulado coletadas na zona respiratória dos trabalhadores através do uso de porta-filtro (tipo cassete) de $37 \mathrm{~mm}$ de diâmetro contendo filtros de membrana de PVC de $5 \mu \mathrm{m}$ de poro acoplados a ciclones de náilon de $10 \mathrm{~mm}$ para a coleta da fração respirável da poeira em suspensão, sendo o ar aspirado por meio de bombas de amostragem individual marca SKC-Modelo 224/44XR calibradas para vazão de 1,7L/min, conforme NHO-07 - Calibração de Bombas de Amostragem Individual pelo Método da Bolha de Sabão, de 2002.

Foram coletadas 35 amostras distribuídas da seguinte forma: empresa X (basalto) - 5 amostras no operador de britagem e 7 
amostras no trabalhador do setor de carregamento; empresa Y (basalto) - 7 amostras no operador da britagem primária e 7 amostras no operador da britagem secundária; empresa Z (gnaisse) - 3 amostras no operador de britagem primária, 3 para britagem secundária e 3 no operador do carregamento.

O tempo de avaliação para cada filtro cobriu $75 \%$ da jornada de trabalho diária, correspondendo a 6 horas de duração, não havendo interrupção dos trabalhos durante a amostragem. Para interpretação dos resultados e comparação com os respectivos limites de tolerância, foi feito o ajuste dos valores medidos para 8 horas de exposição. Para tanto, partindo-se da hipótese de que a concentração de poeira $\left(\mathrm{C}_{2}\right)$ seria zero no restante do tempo $\left(\mathrm{t}_{2}\right)$ para a jornada diária de 8 horas, calculou-se a Concentração Média Ponderada pela equação $\mathrm{C}=\left(\mathrm{C}_{1} \times \mathrm{t}_{1}\right)$ $+\left(c_{2} \times t_{2}\right) /\left(t_{1}+t_{2}\right)$, sendo que $c_{1}$ indica a concentração de poeira obtida no tempo de amostragem $t_{1}$ e $c_{2}$, a concentração de poeira no tempo $t_{2}$.

As amostras de poeira coletadas nos filtros passaram por análise obedecendo aos métodos analíticos expostos na NH-03 - Análise gravimétrica de aerodispersóides coletados sobre filtros de membrana, da Fundacentro (2001), para determinação da massa da amostra coletada, e a MHA 01/D - Determinação quantitativa de sílica livre cristalizada por difração de raios-X, da Fundacentro (1989), para determinação do teor de sílica na amostra.

A coleta de poeira para obtenção de imagens através do Microscópio Eletrônico de Varredura - MEV, utilizadas na análise de tamanho e forma das partículas, foi efetuada com a mesma bomba de amostragem, com vazão de $2,0 \mathrm{~L} / \mathrm{min}$, munidas de filtro de policarbonato com poros de $0,2 \mu \mathrm{m}$. O método de preparação das amostras utilizado para obtenção das imagens teve como base Goldstein (1992), efetuando-se metali-

\section{Resultados e Discussões}

Com referência à concentração de poeira respirável para o trabalhador, consideraram-se dois aspectos: o Limite de Tolerância (LT) estabelecido pela NR 15: LT $=8 /$ $\left(\% \mathrm{SiO}_{2}+2\right) \mathrm{em} \mathrm{mg} / \mathrm{m}^{3}$, que depende do percentual de quartzo na poeira; e o Nível de Ação (NA), que é contemplado na NR 09, ambas do Ministério do Trabalho e Em- zação a ouro e utilizando detecção por meio de elétron secundário, a distância de trabalho (WD) de 14,9mm e a tensão de $15 \mathrm{kV}$.

Para avaliar a morfologia das partículas respiráveis coletadas junto aos trabalhadores, foram utilizados três parâmetros: análise de imagens micrográficas obtidas no MEV, razão entre diâmetros máximo e mínimo das partículas e índice de angulosidade. Os diâmetros máximo e mínimo das partículas utilizados para determinar sua regularidade bem como o diâmetro equivalente das partículas utilizado para definir o tamanho das mesmas foram obtidos com aplicação do programa Image-Pró Plus Version 1.3 for Windows nas imagens obtidas no MEV. Foram avaliadas em torno de 600 partículas.

O índice de angulosidade é definido como a razão entre o perímetro e a área da partícula. Para medição dessas variáveis, aplicou-se o AutoCad Versão 2002 nas mesmas imagens

As caracterizações química e petrográfica das rochas, neste estudo, foram realizadas com a análise de 44 amostras coletadas nas frentes de lavra, sendo 08 delas na empresa X, 19 na empresa Y e 17 na empresa Z. Com as análises química e petrográfica das amostras, procurou-se caracterizar as rochas das áreas estudadas, obtendo-se os percentuais dos elementos químicos e a mineralogia.

No estudo petrográfico, 20 lâminas polidas foram analisadas em microscópio óptico de luz refletida.

Na análise estatística, utilizou-se o software SPSS Versão 11.0, estabelecendo-se índice de confiança de $95 \%(\alpha=0,05)$. Para prova da igualdade das médias, utilizou-se o teste não paramétrico de Mann-Whitinev para o índice de angulosidade e razão dos diâmetros das partículas. Para o diâmetro equivalente, optou-se pelo teste paramétrico "T" de Student. prego - MTE (BRASIL, 2002). O nível de ação para agentes químicos corresponde a $50 \%$ do LT.

Analisando os valores das concentrações de poeira conforme mostrados na Tabela 1, pode-se observar que a Empresa $\mathrm{X}$ apresenta $33 \%$ da poeira respirável aci- 
ma do Limite de Tolerância e 41\% acima do Nível de Ação. Com relação à Empresa $\mathrm{Y}, 64 \%$ dos valores medidos na poeira respirável não obedecem ao LT, enquanto $21 \%$ superam o NA. Para os valores obti- dos na Empresa Z, 44\% da poeira respirável encontram-se acima do LT, com $22 \%$ mostrando-se acima do NA. Para melhor visualização e compreensão, poderá ser observada a Figura 1.

Tabela 1 Valores obtidos nas avaliações ambientais para as empresas X, Y e Z

\begin{tabular}{ccccc}
\hline Composto & $\begin{array}{c}\text { Empresa } \\
\text { Basalto (\%) }\end{array}$ & $\begin{array}{c}\text { EmpresaY } \\
\text { Basalto (\%) }\end{array}$ & $\begin{array}{c}\text { Empresa Z } \\
\text { Diabásio (\%) }\end{array}$ & $\begin{array}{c}\text { Empresa Z } \\
\text { Gnaisse (\%) }\end{array}$ \\
\hline $\mathrm{SiO}_{2}$ & 50,107 & 50,447 & 47,296 & 67,763 \\
$\mathrm{Na}_{2} \mathrm{O}$ & 2,369 & 2,465 & 2,391 & 3,038 \\
$\mathrm{~K}_{2} \mathrm{O}$ & 1,201 & 0,933 & 0,976 & 4,782 \\
$\mathrm{MgO}$ & 4,887 & 5,331 & 5,031 & 0,634 \\
$\mathrm{Al}_{2} \mathrm{O}_{3}$ & 11,920 & 12,257 & 13,432 & 12,024 \\
$\mathrm{P}_{2} \mathrm{O} 5$ & 0,277 & 0,247 & 0,314 & 0,306 \\
$\mathrm{PF}$ & 1,089 & 1,169 & 1,363 & 1,057 \\
\hline Total & 99,599 & 99,868 & 97,412 & 100,126 \\
\hline
\end{tabular}

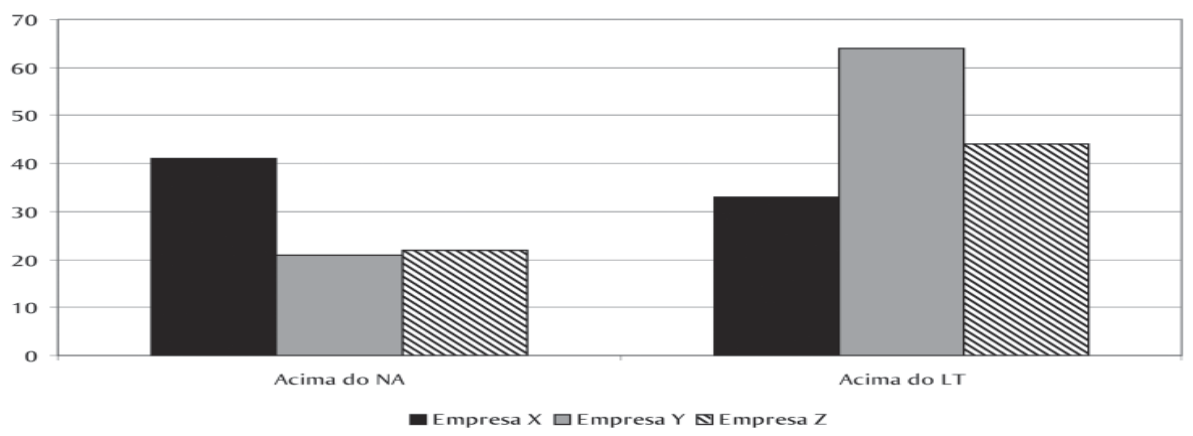

Figura 1 Percentuais do nível de ação e do limite de tolerância obtidos para concentração na poeira respirável para as empresas $\mathrm{X}, \mathrm{Y}$ e Z

O percentual de $\mathrm{SiO}_{2}$ livre na porção da poeira respirável, ou seja, menor que $10 \mu \mathrm{m}$, coletada junto aos trabalhadores apresentou no basalto valores que variam de $1 \%$ a $5,4 \%$, provavelmente proveniente do preenchimento das amígdalas do topo do derrame, enquanto para o gnaisse a maioria $(77,7 \%)$ dos valores de $\mathrm{SiO}_{2}$ livre encontra-se acima de $10 \%$, fato este que, com base em De Capitani (1996) e Funasa (2002), evidencia maior risco de formação de silicose clássica para os trabalhadores expostos à poeira de gnaisse.

Para que ocorresse a necessária confirmação dos tipos de rocha que estavam sendo estudadas, procederam-se às análises químicas e petrográficas das amostras coletadas nas áreas de estudo. Pode-se ob- servar, pelos dados apresentados na Tabela 2, que a distribuição do $\mathrm{SiO}_{2}$ nas amostras é simétrica com relação ao basalto (empresas X e Y) e para o diabásio (empresa Z), mostrando valor em torno de 50\%. O valor de $\mathrm{SiO}_{2}$ apresentado para o gnaisse diferencia para uma quantidade maior, mostrando um valor de aproximadamente $68 \%$. Porém não representa que todo $\mathrm{SiO}_{2}$ é livre. Para o $\mathrm{Fe}_{2} \mathrm{O}_{3}$ os valores apresentam uma certa regularidade nas três primeiras amostras, apresentando para o gnaisse um valor bem inferior aos demais. O mesmo ocorre para o $\mathrm{CaO}$ e $\mathrm{MgO}$. Os valores coincidem com os demonstrados na literatura, conforme Ruegg (1969). A petrografia confirmou tratar-se de basaltos nas empresas X e Y e, na empresa Z, diabásios e gnaisses. 
Tabela 2 Análise química: percentual médio do basalto, do diabásio e do gnaisse provenientes das diferentes empresas

\begin{tabular}{cccccccccc}
\hline \multicolumn{3}{c}{ EmpresaX } & \multicolumn{3}{c}{ EmpresaY } & \multicolumn{3}{c}{ EmpresaZ } \\
& $\begin{array}{c}\mathrm{SiO}_{2} \\
(\%)\end{array}$ & $\begin{array}{c}\text { Concentração } \\
m g / m^{3}\end{array}$ & $\begin{array}{c}L T^{*} \\
m g / m^{3}\end{array}$ & $\begin{array}{c}\mathrm{SiO}_{2} \\
(\%)\end{array}$ & $\begin{array}{c}\text { Concentração } \\
m g / m^{3}\end{array}$ & $\begin{array}{c}L T^{*} \\
m g / m^{3}\end{array}$ & $\begin{array}{c}\mathrm{SiO}_{2} \\
(\%)\end{array}$ & $\begin{array}{c}\text { Concentração } \\
m g / m^{3}\end{array}$ & $\begin{array}{c}L^{*} \\
m g / m^{3}\end{array}$ \\
\hline 01 & 3,80 & 1,45 & 1,37 & 2,70 & 3,18 & 1,70 & 11,55 & 5,20 & 0,59 \\
02 & 2,20 & 2,25 & 1,90 & 2,00 & 2,45 & 2,00 & 10,30 & 3,60 & 0,65 \\
03 & 1,00 & 2,37 & 2,66 & 2,00 & 2,45 & 2,00 & 13,09 & 2,60 & 0,53 \\
04 & 1,90 & 1,32 & 2,05 & 2,70 & 1,81 & 1,70 & 10,90 & 0,28 & 0,62 \\
05 & 5,00 & 0,43 & 1,14 & 3,00 & 0,80 & 1,60 & 8,66 & 0,85 & 0,75 \\
06 & 5,40 & 1,80 & 1,08 & 3,30 & 0,73 & 1,50 & 12,00 & 0,27 & 0,57 \\
07 & 5,00 & 1,12 & 1,14 & 2,90 & 0,85 & 1,63 & 4,34 & 0,56 & 1,26 \\
08 & 2,41 & 2,00 & 1,81 & 1,80 & 2,79 & 2,10 & 10,90 & 0,45 & 0,62 \\
09 & 3,20 & 0,75 & 1,53 & 3,12 & 1,39 & 1,56 & 10,50 & 0,48 & 0,64 \\
10 & 2,41 & 1,00 & 1,81 & 4,50 & 1,07 & 1,23 & - & - & - \\
11 & 1,07 & 1,38 & 2,60 & 2,70 & 1,81 & 1,70 & - & - & - \\
12 & 4,40 & 0,49 & 1,25 & 2,30 & 2,10 & 1,86 & - & - & - \\
13 & - & - & - & 2,30 & 2,15 & 1,86 & - & - & - \\
14 & - & - & - & 1,80 & 2,67 & 2,10 & - & - & - \\
\hline
\end{tabular}

*LT: Limite de Tolerância.

Analisando 60 imagens obtidas no MEV, pode-se constatar, para o basalto, que as partículas apresentam-se subédricas a euédricas, com faces bem definidas e pouco fraturadas. Comparando-se com a poeira relativa ao gnaisse, observa-se que há

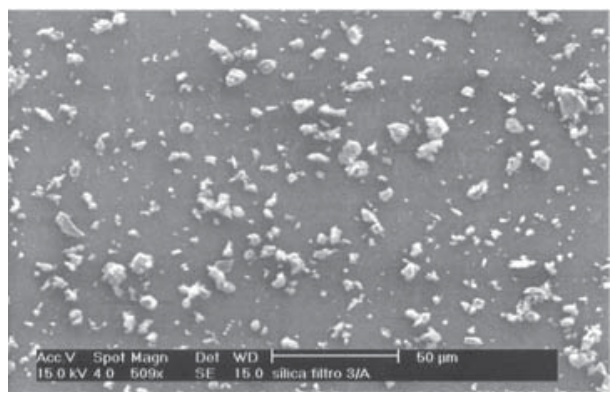

Figura 2 Imagem da poeira do basalto obtida através do MEV

Para confirmação dessa diferença na morfologia entre as partículas das rochas estudadas, aplicaram-se dois parâmetros: razão entre os diâmetros máximo e mínimo das partículas respiráveis e o índice de angulosidade.

Considerou-se que, quanto mais a razão dmáx/dmin for superior à unidade, menos esférica será a partícula. Observando-se a Figura 4 , constata-se que as partículas de gnaisse uma diferença tanto na morfologia, quanto no hábito, já que as partículas de gnaisse em sua maioria apresentam-se anédricas, fibrosas, mais fragmentadas e com forma mais irregular, conforme exemplificado nas Figuras 2 e 3.

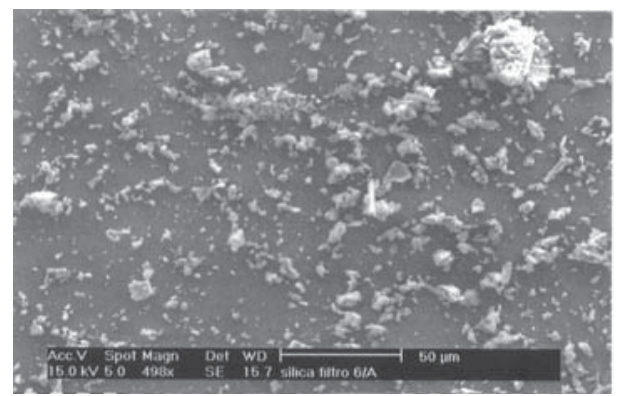

Figura 3 imagem da poeira de gnaisse obtida através do MEV

mostram maior valor apresentando, portanto, menor esfericidade. Considerando apenas os valores da razão dos diâmetros mais próximos de um (1,0), ou seja, entre 1,0 e 1,5, as partículas de basalto respondem aproximadamente com 65\%, enquanto para o gnaisse apenas $10 \%$ das partículas encontram-se dentro desse intervalo. Observando-se todos os intervalos, constata-se maior esfericidade das partículas de basalto. 


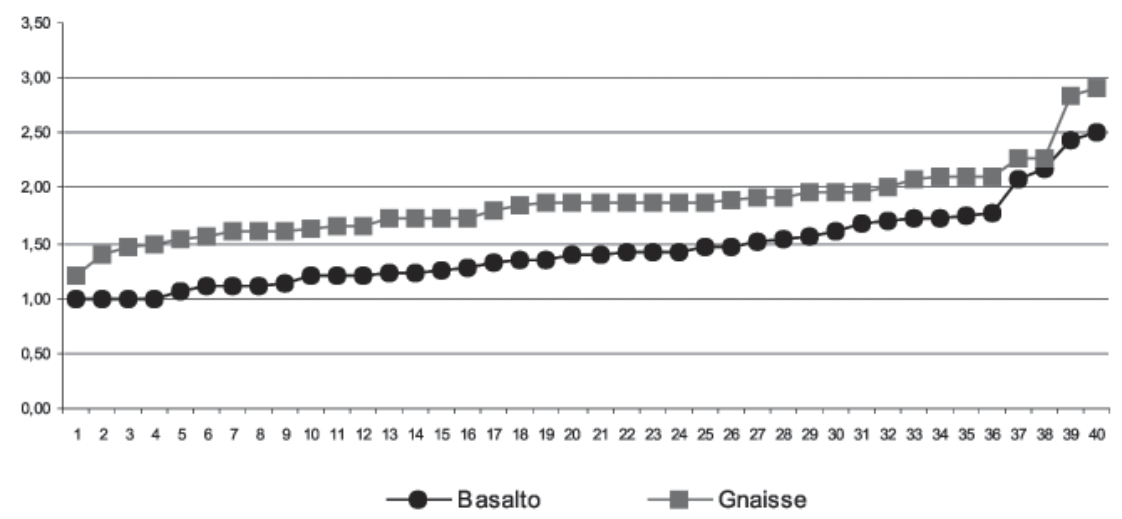

Figura 4 Razões dos diâmetros máximo e mínimo das partículas respiráveis de basalto e gnaisse

$\mathrm{O}$ índice de angulosidade, razão entre o perímetro e a área da seção da partícula, foi utilizado para determinação da regularidade das partículas, considerando-se que, quanto maior for o valor desse índice mais irregular será a partícula. A Figura 5 mostra a diferença de valores em ordem crescente dos índices de angulosidade, podendo-se observar que os valores são maiores para as partículas de gnaisse, mostrando maior irregularidade que as partículas do basalto. Essa diferença acentua-se para os índices com valores maiores.

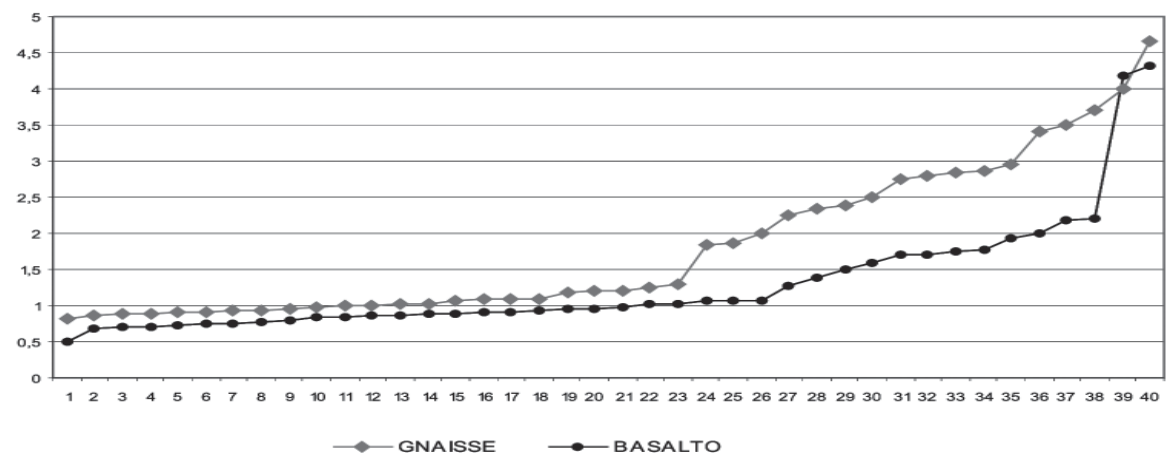

Figura 5 Comparativo dos índices de angulosidade para as partículas respiráveis de basalto e gnaisse

Segundo Santos (2001), o diâmetro equivalente é o parâmetro utilizado para descrever uma partícula tridimensional irregular por meio de um único número, existindo vários métodos para medição do diâmetro de partículas irregulares. Neste caso aplicou-se o programa Image-Pró Plus
Version 1.3 para Windows para determinar os valores do tamanho dos diâmetros equivalentes das partículas coletadas.

Definiu-se para análise o intervalo entre 0,5 e $3,0 \mu \mathrm{m}$, ou seja, aquele em que as partículas podem ficar mais intensamente retidas nos brônquios e alvéolos.

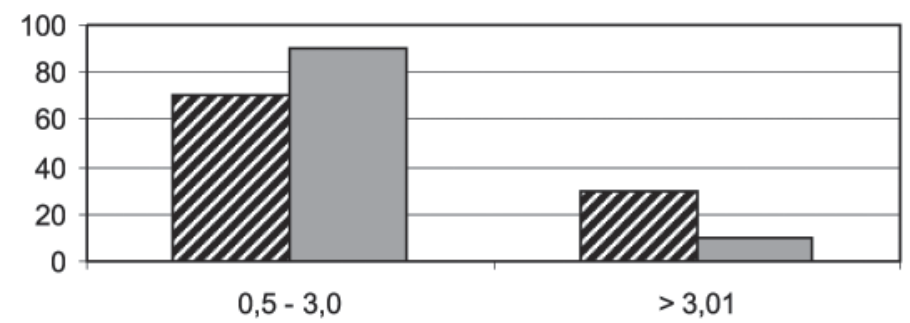

Intervalos de diâmetros (micrômetros)

$\triangle$ Basalto $\square$ Gnaisse

Figura 6 Comparação dos diâmetros equivalentes entre as partículas de basalto e gnaisse 
Conforme mostra a Figura 6, constata-se que $90 \%$ das partículas de gnaisse encontram-se no intervalo estabelecido entre $0,5 \mathrm{e}$ 3,0 $\mu \mathrm{m}$. Para as partículas de basalto, esse número se reduz para 70\%. Portanto, o gnaisse apresenta maior quantidade de partículas no intervalo de tamanho mais prejudicial ao sistema respiratório. Pode-se observar comportamento bimodal das partículas de basalto e monomodal das do gnaisse.

\section{Conclusões}

O presente trabalho comparou os dois tipos de rochas mais utilizadas na produção de brita no Paraná relativamente às concentrações de poeira, aos teores de sílica, ao tamanho e à forma das partículas, pois esses são parâmetros que têm influência expressiva no desenvolvimento de doenças pulmonares pelos trabalhadores de pedreiras.

Os valores para concentração de poeira no ambiente de trabalho mostraram que $33 \%$ da poeira respirável na empresa X (basalto), $64 \%$ na empresa Y (basalto) e $44 \%$ na empresa $Z$ (gnaisse) encontram-se acima do limite de tolerância aceitável para os trabalhadores de acordo com a Norma Regulamentadora 15, em seu anexo 12, aprovada pela Portaria 3.214 de 08/06/1978 do Ministério do Trabalho e Emprego.

Com a análise das amostras coletadas nas frentes de lavra, ou seja, da rocha bruta, constatou-se que o teor de $\mathrm{SiO}_{2}$ para o basalto apresenta-se em média com valor de 50\%. Para o gnaisse, o valor médio foi de $68 \%$. Porém não significa, é claro, que tudo seja sílica livre. Mostrou-se que as rochas das pedreiras estudadas apresentam uma composição típica para suas litologias, conforme desejado para o presente estudo.

Quanto ao teor de $\mathrm{SiO}_{2}$ livre na fração respirável de poeira no basalto, o maior

\section{Referências Bibliográficas}

ALGRANTI, E.; CAPITANI, E. M. de; \& BAGATIN, E. Sistema respiratório. In: Patologia do trabalho. Rio de Janeiro: Atheneu, 1995. p. 89-137.

ALGRANTI, E.; \& CARNEIRO, A. P. S. EXposição à sílica e silicose. São Paulo: Fundacentro, 2002. Apresentado no Curso de Prevenção da Silicose.

ASSOCIAÇÃO BRASILEIRA DE NORMAS TÉCNICAS (ABNT). NBR-7211: Agregado para concreto. Rio de Janeiro: ABNT, 1983.

BASTARACH, E. Silicose et déspitage, 2002. Disponível em: http://digitalfire.com/ valor obtido foi 5,4\%, provavelmente em decorrência do material de preenchimento das amígdalas que ocorrem no topo do derrame. A presença de alguns grãos de quartzo disseminados é bastante comum em rochas basálticas toleíticas. Para o gnaisse, praticamente todos os valores encontramse acima de $10 \%$.

Quanto à morfoscopia, o gnaisse apresenta nitidamente partículas com forma mais irregular e fibrosa. Quanto à granulometria, o percentual de partículas com tamanho propício à deposição nos brônquios e alvéolos se apresenta mais elevado no gnaisse quando comparado ao basalto, o que pode ser evidenciado pelo tratamento estatístico dos índices que foram aqui propostos para quantificar essas feições.

De acordo com os resultados das análises efetuadas, ou seja, concentração, tamanho e forma das partículas, pode-se concluir que a poeira respirável proveniente do gnaisse apresenta situação de risco maior para o sistema respiratório dos trabalhadores que a poeira de basalto. Observando-se o teor de $\mathrm{SiO}_{2}$, a poeira de gnaisse apresenta risco potencial de formação de nódulos silicóticos (silicose clássica), enquanto a poeira de basalto apresenta risco potencial de provocar pneumoconioses por poeiras mistas. education/toxicity/silise.ht. Acesso em: 25 fev. 2003.

BRAILE, V. V. et al. Poluição do ar causada pela operação de pedreiras no município do Rio de Janeiro. Rev. bras. saúde ocup., v. 7, n. 27, p. 204-218, 1979.

BRASIL. Ministério do Trabalho e Emprego. Portaria 3.214 de julho 1978. Normas regulamentadoras de segurança e saúde no trabalho - NR 15. Disponível em: http:// www.tem.gov.br./temas/segsau/legislação/ normas/default.asp. Acesso em: 10 out. 2002. 
CARNEIRO, A. P. S. Silicose: Perfil de 326 pacientes expostos à sílica atendidos ambulatorialmente. Belo Horizonte: HC-UFMG, 2001. 15p. Relatório técnico.

CUNHA, S. B.; \& GUERRA, A. J. T. Geomorfologia do Brasil. Rio de Janeiro: Bertrand Brasil, 1998.

DE CAPITANI, E. M. et al. Toxicologia da sílica. J. Pneumol. v. 22, n. 4, p. 185-194, 1996.

DEPARTAMENTO NACIONAL DA PRODUÇÃO MINERAL (DNPM). Anuário Mineral Brasileiro. Brasília, 2001.

EMPRESA PAULISTA DE PLANEJAMENTO METROPOLITANO (EMPLASA). Pedreiras em áreas urbanas: Importância e efeitos. São Paulo, 1987.

FUNDAÇÃO JORGE DUPRAT FIGUEIREDO DE SEGURANÇA E MEDICINA DO TRABALHO (FUNDACENTRO). NHT-02 $A / E$ : Avaliação da exposição ocupacional à aerodispersóides. São Paulo: Fundacentro, 1984.

MHA 01/D: Determinação quantitativa de sílica livre cristalizada por difração de raios-X. São Paulo: Fundacentro, 1989.

Riscos Químicos. São Paulo: Fundacentro, 1995.

. NH-03: Análise gravimétrica de aerodispersóides coletados sobre filtros de membrana da Fundacentro. São Paulo: Fundacentro, 2001.

. NHO-07: Calibração de bombas de amostragem individual pelo método da bolha de sabão. São Paulo: Fundacentro, 2002.

FUNDAÇÃO NACIONAL DE SAÚDE (FUNASA). Pneumoconioses: aspectos epidemiológicos, 2002. Disponível em: http:// www.funasa.gov.br/guia_epi/htm/doenças/ pneumoconioses. Acesso em: 11 mar. 2003.

GOELZER, B. I. F. Introdução à tecnologia de controle em saúde ocupacional. In: SEMINÁRIO INTERNACIONAL SOBRE EXPOSIÇÃO À SÍLICA. Curso de prevenção e controle de riscos/poeiras, 2000. Curitiba: [s.n.], 2000.
GOLDSTEIN, J. I. et al. Scanning electron microscopy and X-Ray microanalysis. New York: Plenum Press, 1992.

INSTITUTO AGRONÔMICO DO PARANÁ (IAPAR). Condições climáticas da região de Londrina. Londrina, 2001. Disponível em: http://www.londrina.pr.gov.br/planejamento/perfil-2001/e-caracteristicas.php3. Acesso em: 08 out. 2003.

INSTITUTO AMBIENTAL DO PARANÁ (IAP). Relatório da qualidade do ar na região metropolitana de Curitiba. Curitiba, 2001. 46 p. Relatório técnico.

INTERNATIONAL AGENCY FOR RESEARCH ON CANCER. Sílica, some silicates, coal dust and Para-Aramid fibrils. Lyon: IARC, 1997. Monographs on the evaluation of the carcinogenic risk of chemicals to humans, v.38.

MAACK, R. Geografia física do estado do Paraná. Curitiba: Banco de Desenvolvimento do Paraná, 1968.

MINERAIS DO PARANÁ S.A. Perfil da indústria de agregados. Curitiba, 1999. 76p.

RUEGG, N. R. Aspectos geoquímicos, mineralógicos e petrográficos de rochas basálticas da Bacia do Paraná. 1969. Tese (Doutorado) - Instituto de Geociências, Universidade de São Paulo, São Paulo, 1969.

SANTOS, A. M. A. O tamanho das partículas de poeira suspensas no ar dos ambientes de trabalho. São Paulo: Fundacentro, 2001. Adaptação da dissertação de mestrado apresentada no curso de Pós-Graduação em Engenharia de Minas e Metalurgia da Universidade Federal de Minas Gerais.

SANTOS, W. J. Recuperação de áreas mineradas: um enfoque prevencionista para mineração. In: CONGRESSO BRASILEIRO DE GEOLOGIA, 6, 1988, Pará. Anais.... Belém, 1988. p. 1983-1988.

SIGA JÚNIOR, O. et al. O Complexo Atuba. Bol. IG-USP, Série Científica, n. 26, p. 6998. 1995.

SOUNIS, E. Manual de higiene e medicina do trabalho. São Paulo: McGraw-Hill, 1991.

VALVERDE, F. M. Agregados para construção civil. Balanço Mineral Brasileiro. Brasília: DNPM, 2001/2002. p. 42-47. 